Supplement of The Cryosphere, 9, 1685-1699, 2015

http://www.the-cryosphere.net/9/1685/2015/

doi:10.5194/tc-9-1685-2015-supplement

(C) Author(s) 2015. CC Attribution 3.0 License.

(c) (i)

The Cryosphere

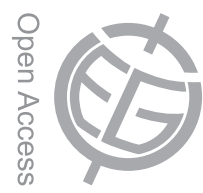

Supplement of

\title{
Black carbon in snow in the upper Himalayan Khumbu Valley, Nepal: observations and modeling of the impact on snow albedo, melting, and radiative forcing
}

\section{H.-W. Jacobi et al.}

Correspondence to: H.-W. Jacobi (hans-werner.jacobi@ujf-grenoble.fr)

The copyright of individual parts of the supplement might differ from the CC-BY 3.0 licence. 


\section{Supplement}

The supplement includes ten figures (S1a, S1b, S1c, S2a, S2b, S3a, S3b, S4, S5, and S6) and three tables (S1, S2, and S3).

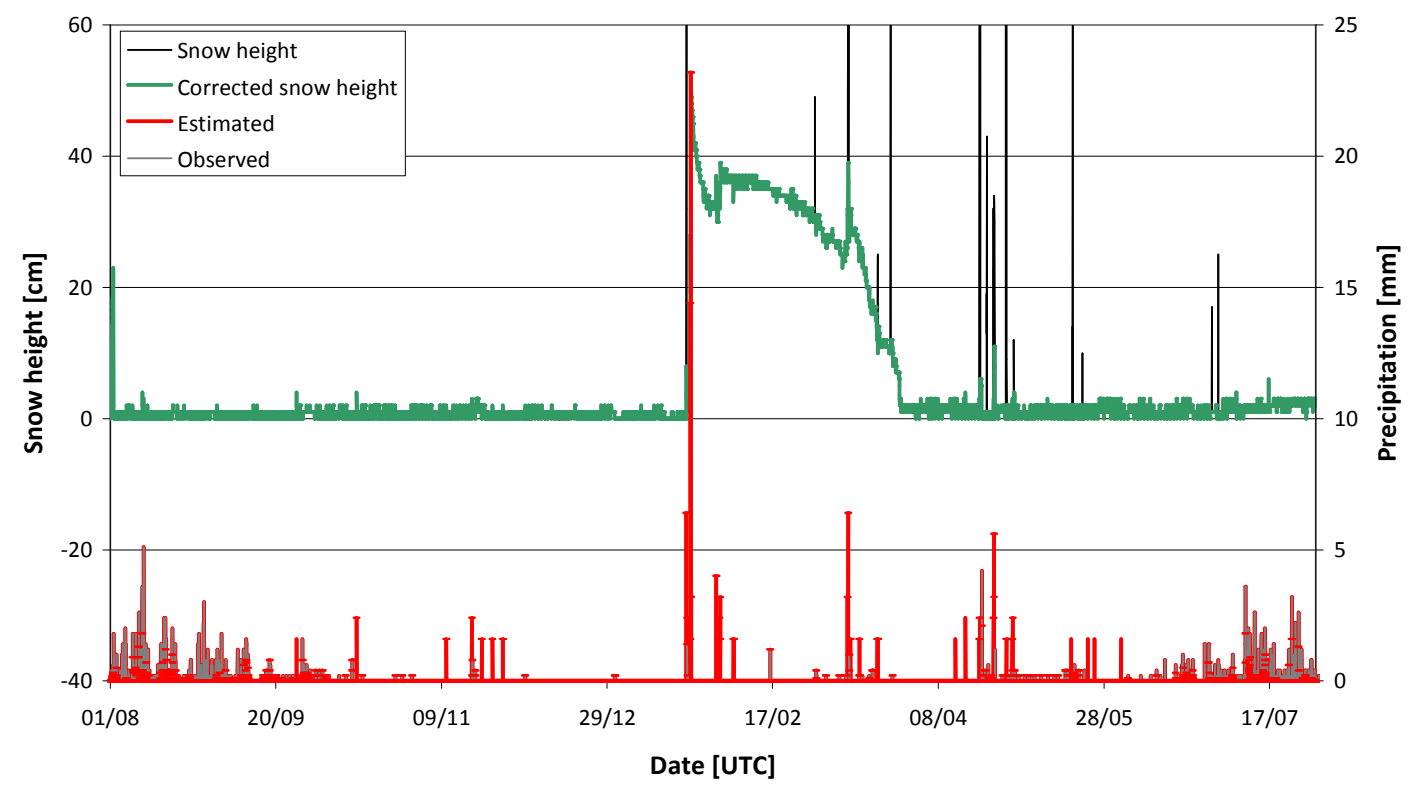

Figure S1a. Time series of recorded and corrected snow height (left axis) and precipitation (right axis) at NCO-P for the winter season 2004/05. The green line indicates the corrected snow height after removal of the recorded individual peaks (black lines). Maximum recorded snow height was $200 \mathrm{~cm}$. The red line corresponds to the corrected time series of precipitation in comparison to the recorded precipitation (grey line). Horizontal red bars indicate solid precipitation. 


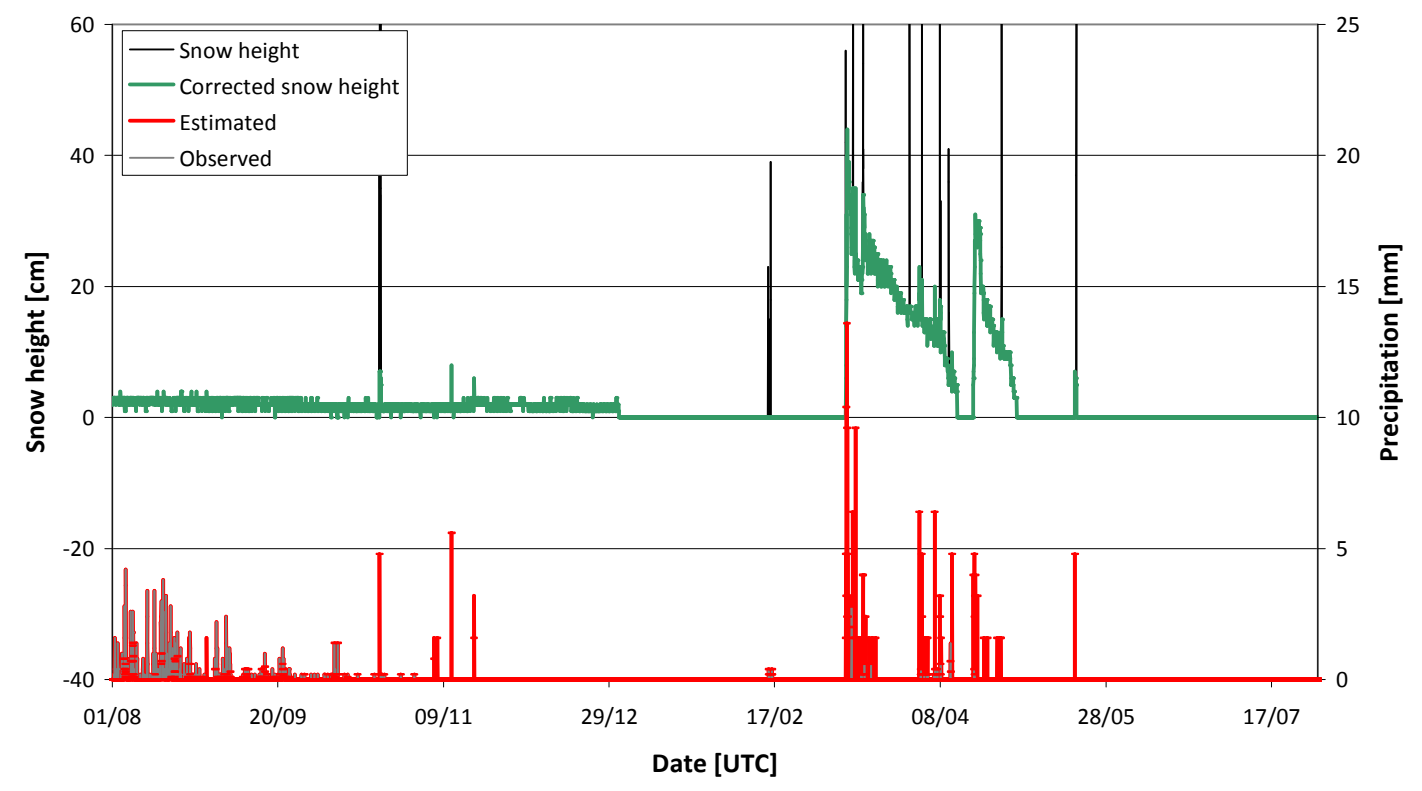

Figure S1b. Same as Figure S1a, but for 2005/06. Maximum recorded snow height was $177 \mathrm{~cm}$.

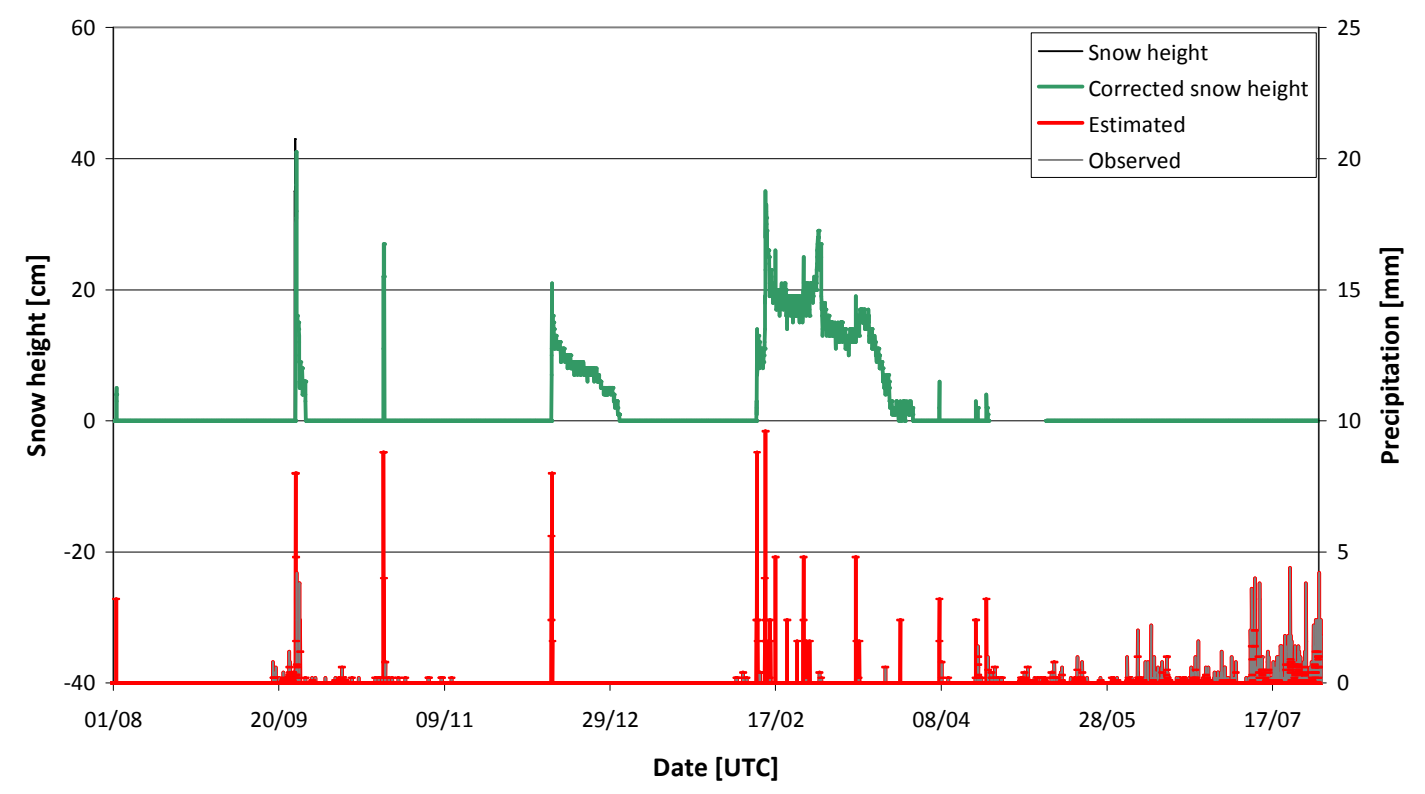

Figure S1c: Same as Figure S1a, but for 2006/07. 


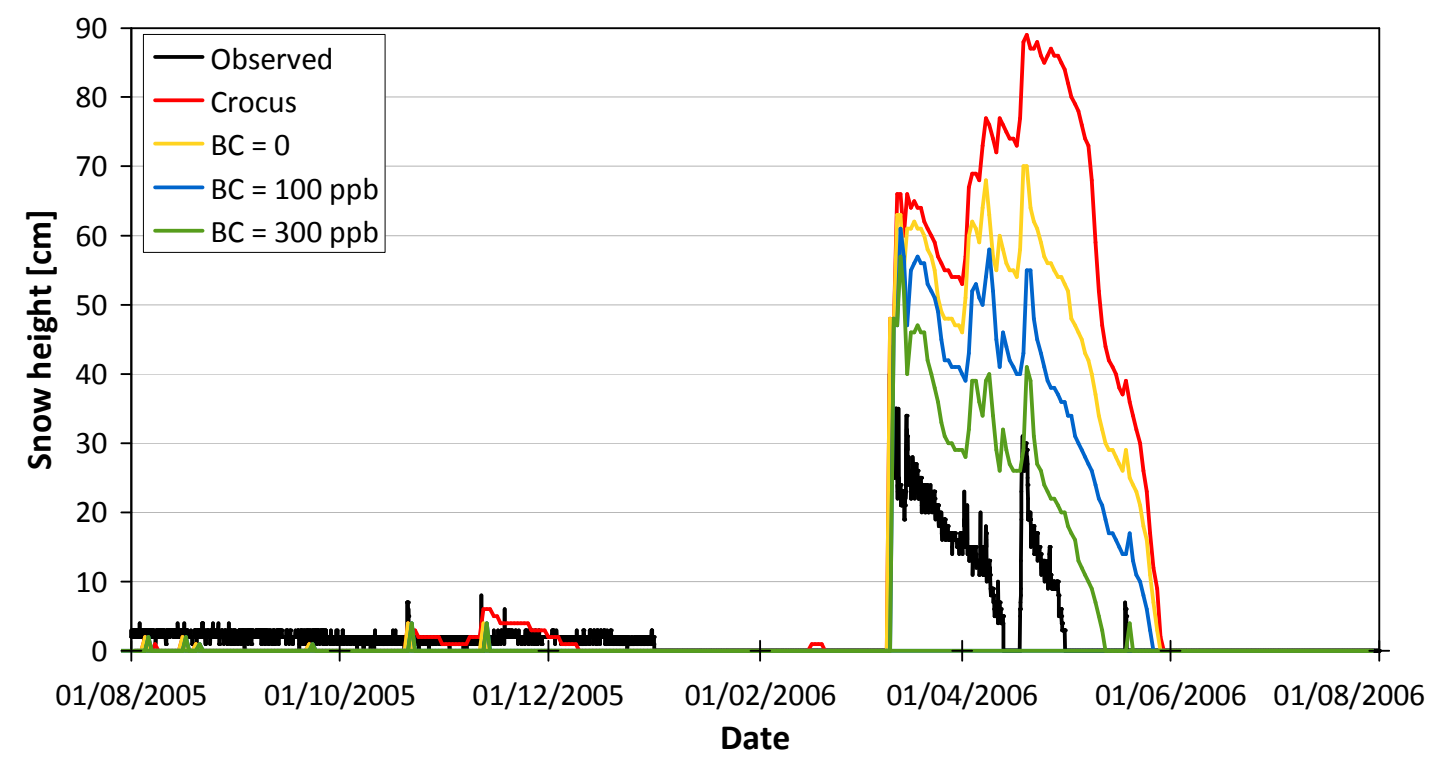

Figure S2a. Comparison of observed (black) and simulated snowpack heights at NCO$P$ for the winter season 2005/06. Simulations were performed with the standard Crocus model (red) and with the upgraded model including radiative transfer with constant BC concentrations of 0 (yellow), 100 (blue), and 300 ppb (green).

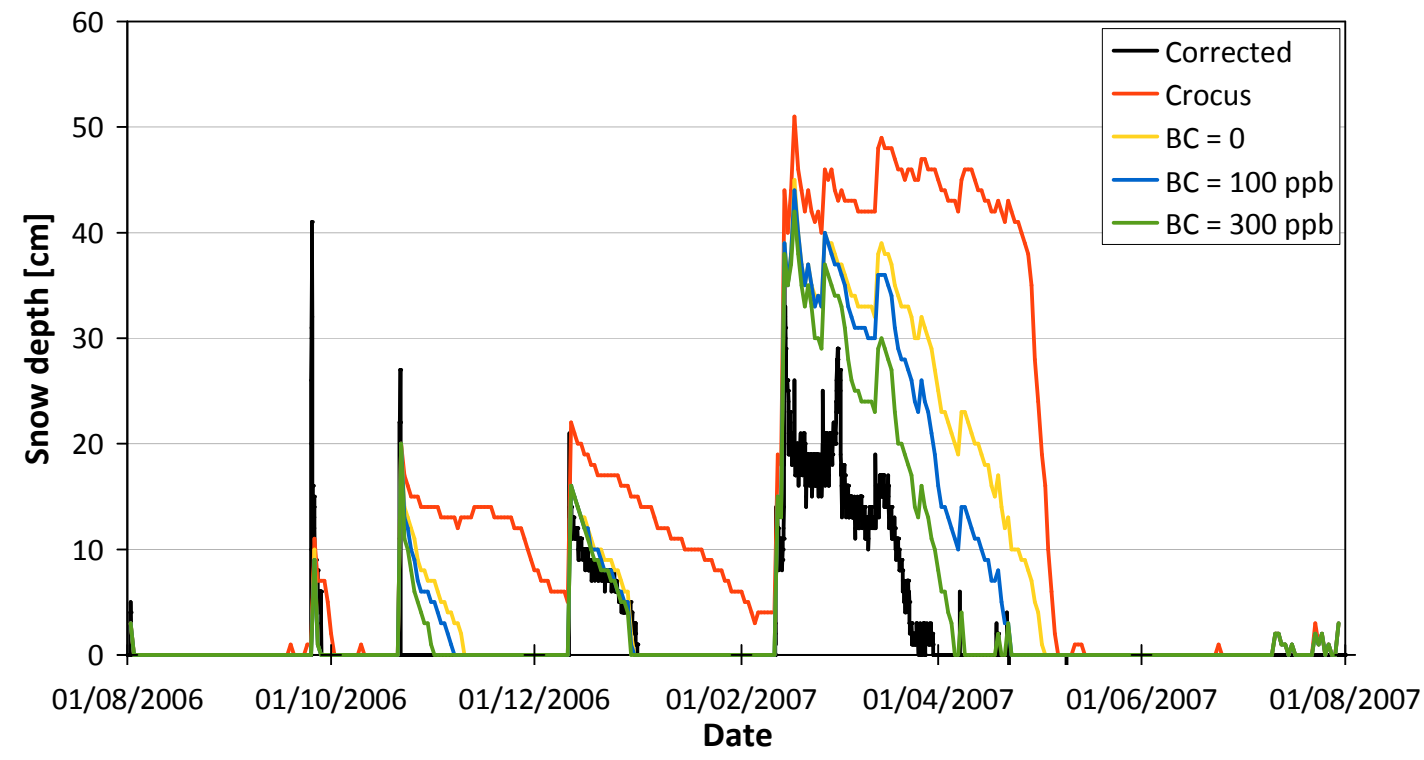

Figure S2b. Same as Figure S2a, but for 2006/07. 


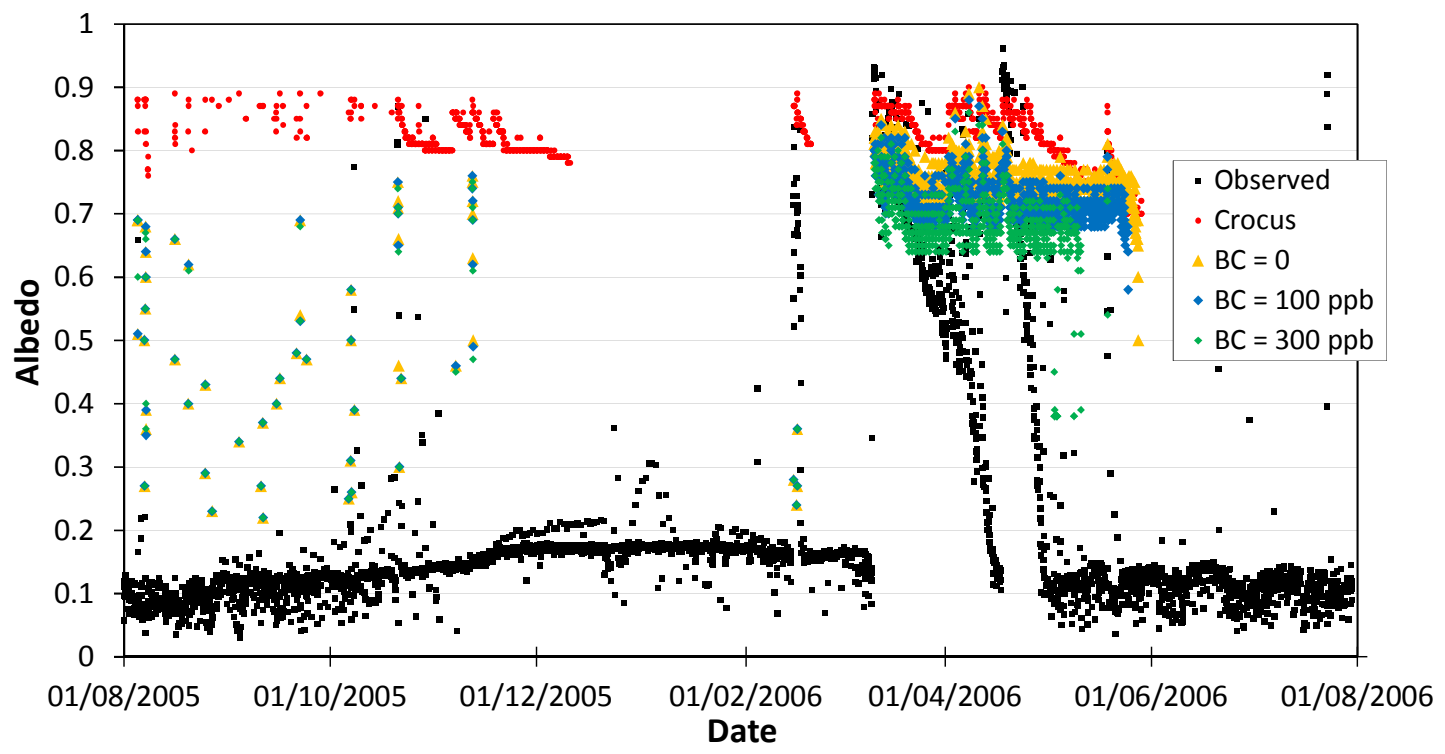

Figure S3a. Comparison of observed (black) and simulated albedo at NCO-P for the winter season 2005/06. Simulations were performed with the standard Crocus model (red) and with the upgraded model including radiative transfer with $\mathrm{BC}$ concentrations of 0 (yellow), 100 (blue), and 300 ppb (green).

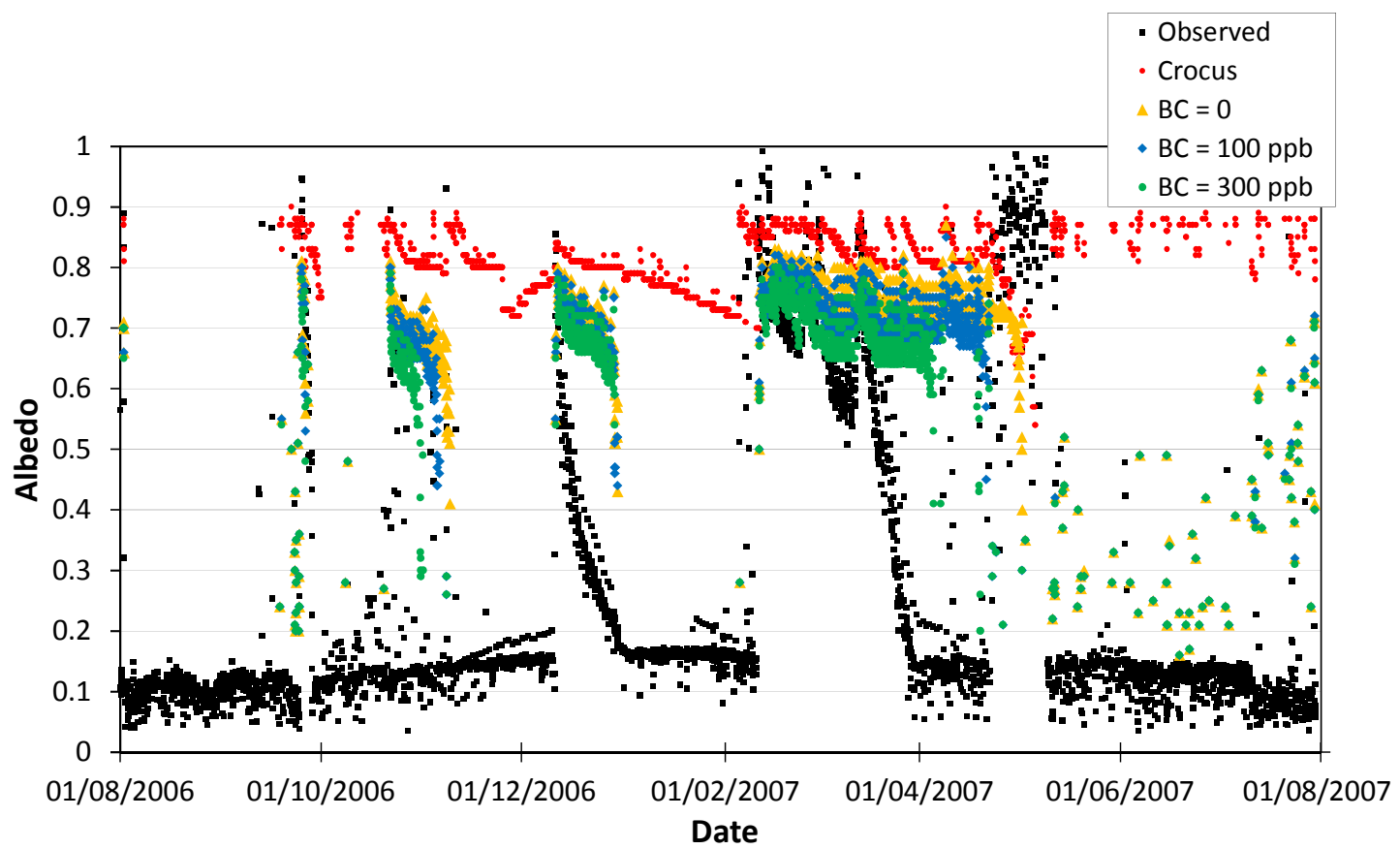

Figure S3b. Same as Figure S3a, but for 2006/07. 


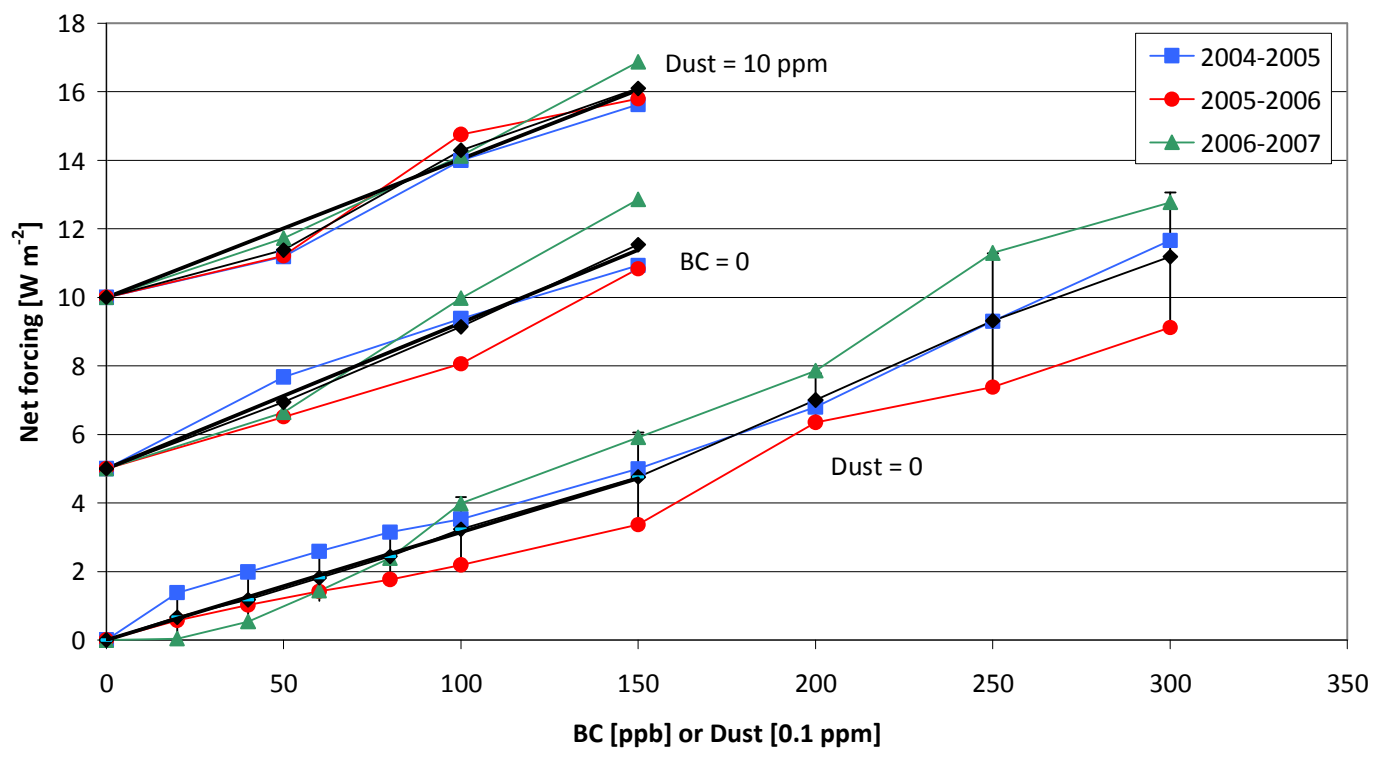

Figure S4. Simulated annual net forcing related to shortwave radiation and latent and sensible heat fluxes due to the presence of $B C$ and dust in the snow. Simulations are performed without dust, without $B C$ (shifted by $+5 \mathrm{~W} \mathrm{~m}^{-2}$ ), and with dust $=10$ $\mathrm{ppm}$ (shifted by $+10 \mathrm{~W} \mathrm{~m}^{-2}$ ). In the last case, the reductions are calculated relative to the case with $\mathrm{BC}=0$ and dust $=10 \mathrm{ppm}$. Black symbols indicate the 3 -yr averages of the net forcing with the error bars representing the standard deviation. Black lines correspond to results of linear regressions forced through the origin for all average values for $B C \leq 150 \mathrm{ppb}$.

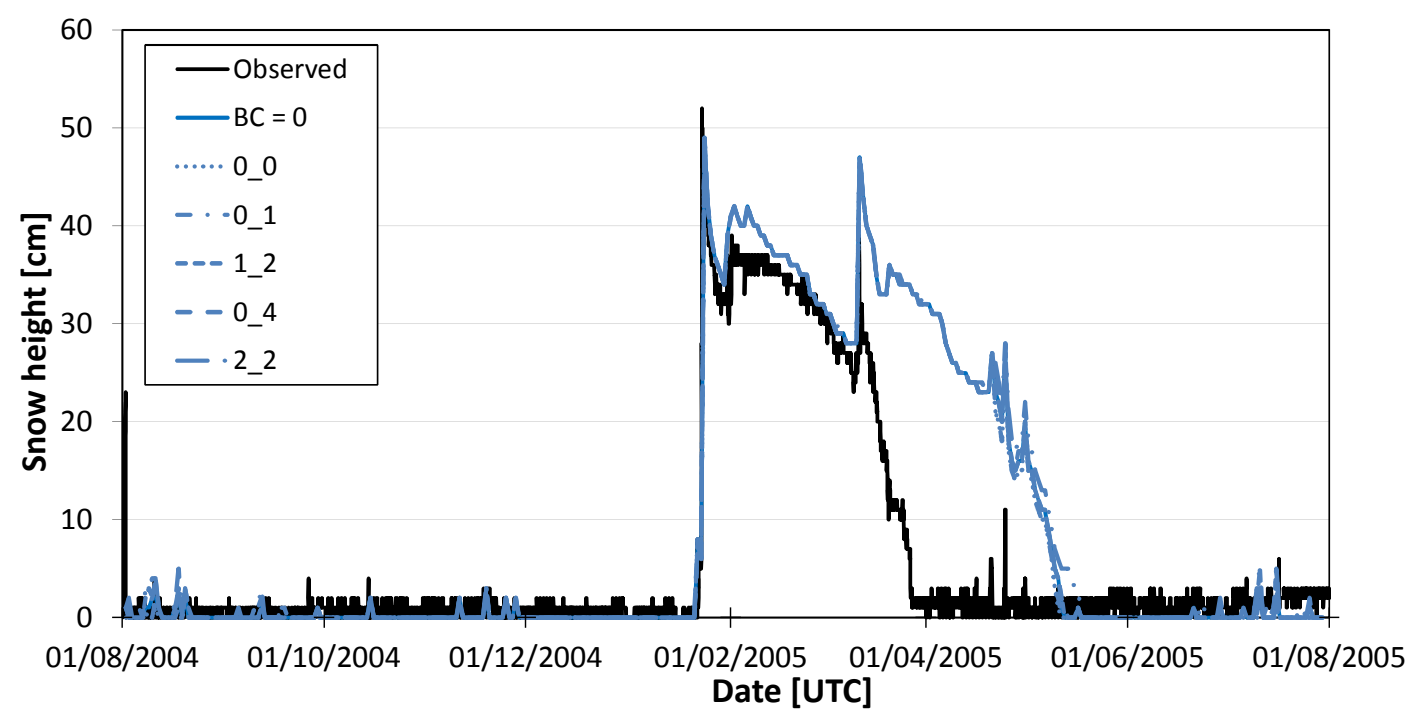

Figure S5. Comparison of observed (black) and simulated snowpack heights at NCO-P for the winter season 2004/05. The blue lines show results of simulations with the upgraded model including radiative transfer with constant BC concentrations of 100 ppb using the standard meteorological forcing data (full line) or forcing data with varying solid precipitation (see Table S1 for further information). 


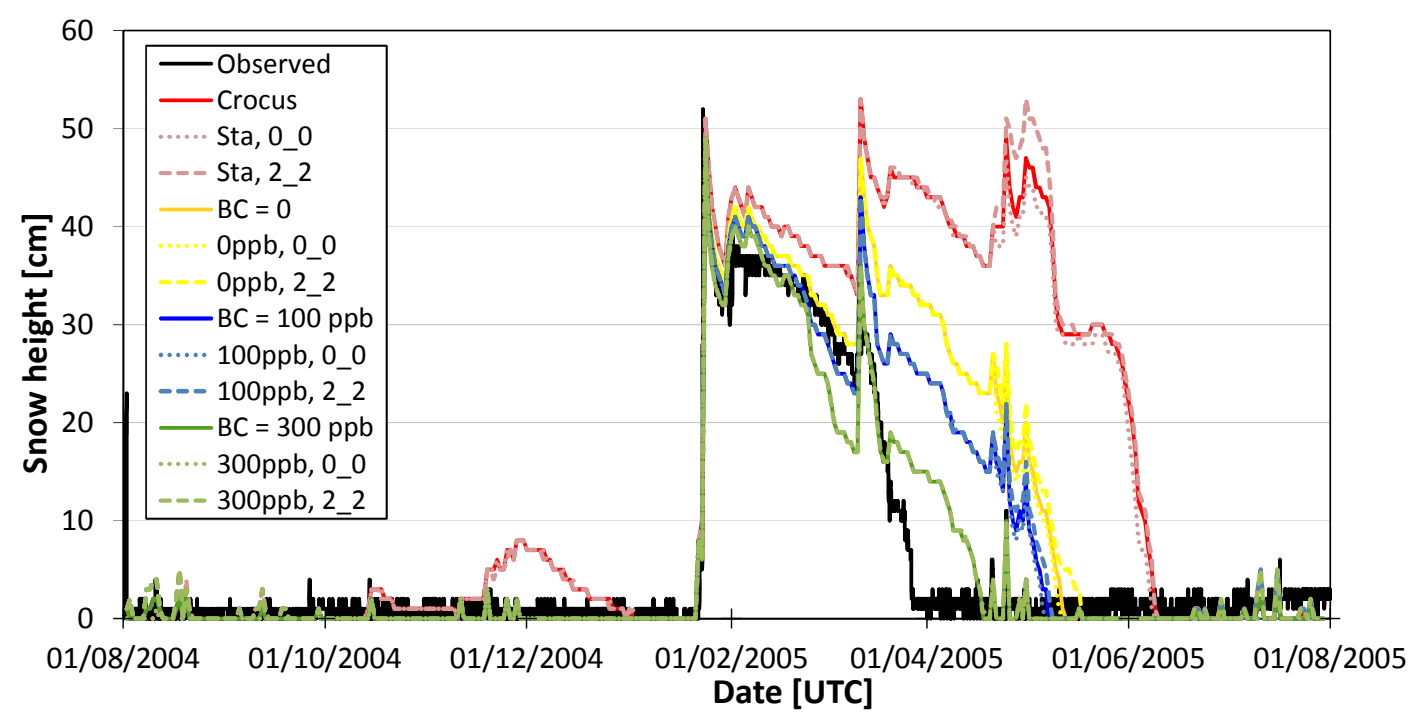

Figure S6. Comparison of observed (black) and simulated snowpack heights at NCO-P for the winter season 2004/05. Full lines show results of simulation with the standard meteorological forcing data and were performed with the standard crocus model (red) and with the upgraded model including radiative transfer with constant $\mathrm{BC}$ concentrations of 0 (yellow), 100 (blue), and $300 \mathrm{ppb}$ (green). Results of the sensitivity runs"0_0" and "2_2" (see Table S1) are shown by dotted and dashed lines. Results of further sensitivity runs are within the range of these two runs.

Table S1. Summary of threshold temperatures for solid, mixed-phase, and liquid precipitation used to generate meteorological forcing data for the snow simulations. At air temperatures below the values in the column "Solid phase" all precipitations are assumed to be solid, at temperatures above the values in the column "Liquid phase" all precipitations are assumed to be liquid. "Mixed phase" gives the range with assumed $50 \%$ solid and $50 \%$ liquid precipitation. Also given are the estimated totals for the solid precipitation. The total annual precipitation for 2004/05 was $491.7 \mathrm{~mm}$. The "Standard" model run correspond to the meteorological forcing data used for all further simulations presented in the manuscript.

\begin{tabular}{|l|c|c|c|c|}
\hline Model run & Solid phase & Mixed phase & Liquid phase & Solid precipitation \\
\hline Standard & $0{ }^{\circ} \mathrm{C}$ & $0-2{ }^{\circ} \mathrm{C}$ & $2{ }^{\circ} \mathrm{C}$ & $204.0 \mathrm{~mm}$ \\
\hline $0 \_0$ & $0{ }^{\circ} \mathrm{C}$ & & $0{ }^{\circ} \mathrm{C}$ & $145.4 \mathrm{~mm}$ \\
\hline $0 \_1$ & $0{ }^{\circ} \mathrm{C}$ & $0-1{ }^{\circ} \mathrm{C}$ & $1{ }^{\circ} \mathrm{C}$ & $166.1 \mathrm{~mm}$ \\
\hline $1 \_2$ & $1{ }^{\circ} \mathrm{C}$ & $1-2{ }^{\circ} \mathrm{C}$ & $2{ }^{\circ} \mathrm{C}$ & $231.5 \mathrm{~mm}$ \\
\hline $2 \_2$ & $2{ }^{\circ} \mathrm{C}$ & & $2{ }^{\circ} \mathrm{C}$ & $275.4 \mathrm{~mm}$ \\
\hline $0 \_4$ & $0{ }^{\circ} \mathrm{C}$ & $0-4{ }^{\circ} \mathrm{C}$ & $4{ }^{\circ} \mathrm{C}$ & $277.6 \mathrm{~mm}$ \\
\hline
\end{tabular}


Table S2. Summary of statistical parameters for the comparison of observed and simulated albedo including bias (simulated - observed), root mean squared errors (RMSE) (simulated - observed), and correlation coefficients for linear regressions of simulated versus observed albedos. All values are calculated for the indicated periods of the winter snowpack for 2004/05, 2005/06, and 2006/07 and for the first month of each period. Averages of all parameters are calculated for the three winter seasons and for the first month periods.

\begin{tabular}{|c|c|c|c|c|c|c|c|c|c|c|c|c|}
\hline \multirow[t]{2}{*}{ Albedo } & \multicolumn{4}{|c|}{ Bias (simulated - observed) } & \multicolumn{4}{|c|}{ RMSE (simulated - observed) } & \multicolumn{4}{|c|}{ Correl. Coeff. (simulated vs. observed) } \\
\hline & Sta & $B C=0$ & $\begin{array}{c}\mathrm{BC}= \\
100 \mathrm{ppb}\end{array}$ & $\begin{array}{c}\mathrm{BC}= \\
300 \mathrm{ppb}\end{array}$ & Sta & $\mathrm{BC}=0$ & $\begin{array}{c}B C= \\
100 \mathrm{ppb}\end{array}$ & $\begin{array}{c}\mathrm{BC}= \\
300 \mathrm{ppb}\end{array}$ & Sta & $B C=0$ & $\begin{array}{c}\mathrm{BC}= \\
100 \mathrm{ppb}\end{array}$ & $\begin{array}{c}\mathrm{BC}= \\
300 \mathrm{ppb}\end{array}$ \\
\hline \multicolumn{13}{|l|}{$2004 / 05$} \\
\hline $22 / 01-01 / 04$ & 0.292 & 0.223 & 0.196 & 0.163 & 0.295 & 0.237 & 0.218 & 0.198 & 0.089 & 0.272 & 0.337 & 0.429 \\
\hline $22 / 01-21 / 02$ & 0.119 & 0.051 & 0.027 & -0.003 & 0.123 & 0.079 & 0.068 & 0.063 & 0.449 & 0.283 & 0.361 & 0.408 \\
\hline \multicolumn{13}{|l|}{$2005 / 06$} \\
\hline $10 / 03-01 / 05$ & 0.262 & 0.180 & 0.147 & 0.109 & 0.281 & 0.217 & 0.196 & 0.179 & 0.346 & 0.428 & 0.438 & 0.440 \\
\hline $10 / 03-09 / 04$ & 0.169 & 0.095 & 0.063 & 0.025 & 0.195 & 0.137 & 0.116 & 0.101 & 0.375 & 0.565 & 0.524 & 0.534 \\
\hline \multicolumn{13}{|l|}{$2006 / 07$} \\
\hline $12 / 02-30 / 03$ & 0.193 & 0.110 & 0.086 & 0.052 & 0.266 & 0.198 & 0.180 & 0.160 & 0.359 & 0.635 & 0.661 & 0.629 \\
\hline $12 / 02-11 / 03$ & 0.104 & 0.021 & 0.000 & -0.034 & 0.185 & 0.120 & 0.106 & 0.091 & 0.504 & 0.536 & 0.597 & 0.604 \\
\hline \multicolumn{13}{|l|}{ Average } \\
\hline Season & 0.249 & 0.171 & 0.143 & 0.108 & 0.280 & 0.217 & 0.198 & 0.179 & 0.265 & 0.445 & 0.479 & 0.500 \\
\hline 1. month & 0.131 & 0.056 & 0.030 & -0.004 & 0.168 & 0.112 & 0.097 & 0.085 & 0.443 & 0.461 & 0.494 & 0.515 \\
\hline
\end{tabular}


Table S3. Summary of statistical parameters for the comparison of observed and simulated albedo including bias (simulated - observed), root mean squared errors (RMSE) (simulated - observed), and correlation coefficients for linear regressions of simulated versus observed albedos for the indicated different model runs using different meteorological forcing data: standard forcing used throughout the manuscript and the sensitivity runs"0_0" and "2_2" (see Table S1). All values are calculated for the indicated periods of the winter snowpack for 2004/05.

\begin{tabular}{|c|c|c|c|c|c|c|c|c|c|c|c|c|}
\hline $\begin{array}{l}\text { Albedo } \\
2004 / 05\end{array}$ & Sta & $\begin{array}{l}\text { Sta, } \\
0 \_0\end{array}$ & $\begin{array}{l}\text { Sta, } \\
2 \_2\end{array}$ & $B C=0$ & $\begin{array}{c}B C=0, \\
0 \_0\end{array}$ & $\begin{array}{c}\mathrm{BC}=0, \\
2 \_2\end{array}$ & $\begin{array}{c}\mathrm{BC}= \\
100 \mathrm{ppb}\end{array}$ & $\begin{array}{c}\mathrm{BC}=100, \\
0 \_0\end{array}$ & $\begin{array}{c}B C=100, \\
2 \_2\end{array}$ & $\begin{array}{c}\mathrm{BC}= \\
300 \mathrm{ppb}\end{array}$ & $\begin{array}{c}\mathrm{BC}=300, \\
0 \_0\end{array}$ & $\begin{array}{c}\mathrm{BC}=300, \\
2 \_2\end{array}$ \\
\hline & Bias (sim & ated - ol & served) & & & & & & & & & \\
\hline $22 / 01-01 / 04$ & 0.292 & 0.291 & 0.292 & 0.223 & 0.223 & 0.223 & 0.196 & 0.196 & 0.196 & 0.163 & 0.163 & 0.163 \\
\hline \multirow[t]{2}{*}{$22 / 01-21 / 02$} & 0.119 & 0.119 & 0.119 & 0.051 & 0.051 & 0.051 & 0.027 & 0.027 & 0.027 & -0.003 & -0.003 & -0.003 \\
\hline & \multicolumn{12}{|c|}{ RMSE (simulated - observed) } \\
\hline 22/01-01/04 & 0.295 & 0.294 & 0.295 & 0.237 & 0.237 & 0.237 & 0.218 & 0.218 & 0.218 & 0.198 & 0.198 & 0.198 \\
\hline \multirow[t]{2}{*}{$22 / 01-21 / 02$} & 0.123 & 0.123 & 0.123 & 0.079 & 0.079 & 0.079 & 0.068 & 0.068 & 0.068 & 0.063 & 0.063 & 0.063 \\
\hline & \multicolumn{12}{|c|}{ Correl. Coeff. (simulated vs. observed) } \\
\hline 22/01-01/04 & 0.089 & 0.107 & 0.086 & 0.272 & 0.269 & 0.275 & 0.337 & 0.339 & 0.346 & 0.429 & 0.425 & 0.429 \\
\hline 22/01-21/02 & 0.449 & 0.449 & 0.449 & 0.283 & 0.283 & 0.283 & 0.361 & 0.361 & 0.361 & 0.408 & 0.408 & 0.408 \\
\hline
\end{tabular}

